\title{
Communication Strategies of Indonesian for Foreign Speaker Students: A Case Study of Turkmenistan and Rwanda Students in Universitas Sebelas Maret
}

\author{
Feny Oktaviani $^{1}$, Andayani ${ }^{2}$, Suyitno $^{3}$ \\ Universitas Sebelas Maret, Indonesia \\ feny.oktaviani01@student.uns.ac.id ${ }^{1}$, bu_anda09@yahoo.co.id ${ }^{2}$, \\ yitsuyitno52@gmail.com ${ }^{3}$
}

\begin{abstract}
Attempt to use the target language is a communication problem for second language learners. Communication strategy is one way to overcome the problem. The research aims to describe and explain the communication strategies used by Indonesian for foreign speaker (BIPA) students from Turkmenistan and Rwanda during BIPA learning. The research is a case study with natural background. Observations of verbal and nonverbal communication from Turkmenistan and Rwanda students were carried out at UPT Bahasa Universitas Sebelas Maret. The result of observation and interview are data for the research. Data analysis techniques used interactive patterns. There are twelve communication strategies used by BIPA students from Turkmenistan and Rwanda (verbal and nonverbal) discovered by the researchers. The two learners have different communication strategies because of different levels of learning, culture, first language, and typeface. The research also found the factors that support and inhibit communication strategies from the students of BIPA.
\end{abstract}

Keywords: Communication Strategy, Verbal, Nonverbal, Foreign, Language

\section{PENDAHULUAN}

Strategi komunikasi merupakan salah satu cara yang diterapkan oleh pemelajar asing dengan tujuan agar bisa berkomunikasi dengan lancar menggunakan bahasa Indonesia baik verbal maupun nonverbal [1]. Dalam interaksi pembelajaran, komunikasi digunakan oleh pemelajar sebagai media untuk melatih dan mengembangkan pengetahuan bahasanya meski masih memiliki keterbatasan. Strategi komunikasi berarti teknis sistematis yang digunakan oleh pemelajar untuk mengungkapkan ide dan gagasannya ketika mengalami kesulitan karena penguasaan bahasa yang belum sempurna [2]. Penggunaan strategi komunikasi dalam pembelajaran bahasa kedua harus memperhatikan (1) tingkat penguasaan bahasa pemelajar, (2) masalah bahasa sumber, (3) kepribadian, (4) situasi belajar [3]. Program BIPA merupakan salah satu upaya internasionalisasi bahasa yang diadakan oleh pemerintah [4]. Adanya program BIPA sangat membuka peluang bagi Indonesia untuk memperkenalkan bahasa dan budaya kepada masyarakat di kancah dunia. Akan tetapi, kegiatan pembelajaran BIPA di Indonesia hingga saat ini masih memiliki banyak kendala yang dipengaruhi oleh latar belakang budaya yang berbeda, tempat belajar, dan bahasa yang digunakan [5]. Semakin banyak kendala dalam interaksi pembelajaran, semakin banyak pula strategi komunikasi yang digunakan oleh pemelajar BIPA untuk meminimalisasi kesenjangan dalam berkomunikasi.

Terdapat fenomena yang terjadi dalam pembelajaran BIPA yang diadakan UPT Bahasa Universitas Sebelas Maret Surakarta. Fenomena tersebut adalah adanya penggunaan strategi 
komunikasi yang digunakan oleh mahasiswa darmasiswa dan mahasiswa BIPA level 2. Sebagai sampel penelitian, peneliti memilih pemelajar asal Turkmenistan untuk mewakili mahasiswa darmasiswa dan mahasiswa asal Rwanda sebagai perwakilan mahasiswa BIPA level 2 untuk diobservasi penggunaan strategi komunikasinya dalam bentuk verbal dan nonverbal. Keduanya menggunakan strategi komunikasi yang berbeda untuk menunjang pembelajaran karena beberapa faktor seperti perbedaan budaya, bahasa, jenis huruf, dan lain-lain. Mahasiswa Turkmenistan memiliki bahasa ibu berupa bahasa Rusia dan menggunakan huruf Kiril di kehidupan sehari-hari. Sedangkan mahasiswa Rwanda memiliki bahasa ibu yakni bahasa Rwanda tetapi bercampur dengan bahasa Inggris. Berbagai bentuk strategi komunikasi yang mereka gunakan menjadi fokus utama dalam penelitian ini. Namun, peneliti juga menemukan fakta di lapangan bahwa penggunaan strategi komunikasi juga memiliki hambatan. Seharusnya, strategi komunikasi mampu mengurangi kesenjangan yang mereka hadapi ketika mereka terlibat dalam interaksi pembelajaran. Akan tetapi pada kenyataannya, penggunaan strategi komunikasi itu sendiri juga memiliki banyak kendala. Adanya rasa takut, kurang percaya diri, atau malu adalah beberapa kendala dari pemelajar yang menyebabkan strategi komunikasi yang digunakan tidak membuahkan hasil maksimal. Terlebih, mahasiswa Turkmenistan sama sekali tidak bisa berbahasa Inggris dan hal ini kerapkali membuatnya merasa takut dan kurang percaya diri. Artinya, maksud dari mereka tetap sulit tersampaikan karena strategi komunikasi yang dipilih ternyata juga mengalami hambatan. Padahal, strategi komunikasi berfungsi sebagai alat untuk membantu pemelajar ketika menghadapi kesulitan berkomunikasi [6].

Strategi komunikasi akan efektif digunakan jika pengguna lebih memiliki kontrol formal terhadap B1. Hal ini diperjelas oleh hasil penelitian [7] yang mengungkapkan bahwa salah satu manfaat adanya strategi komunikasi adalah sebagai upaya pemertahanan bahasa Indonesia selama proses pembelajaran sehingga pemelajar akan memiliki kontrol untuk tidak menggunakan B1 yang mereka miliki. Demikian pula dengan pendapat [5] yang menemukan bahwa semakin pemelajar memiliki kontrol terhadap B1, maka penggunaan strategi komunikasi dapat berjalan dengan baik. Namun pada kenyataannya mahasiswa Turkmenistan dan Rwanda kerapkali tidak mampu mengontrol diri untuk tidak menggunakan B1 dan hal ini justru semakin mempersulit jalannya komunikasi. Mahasiswa Turkmenistan kerapkali tidak sengaja mengatakan berbagai hal menggunakan bahasa Rusia karena ia tidak bisa menggunakan bahasa Inggris dan bahasa Indonesia. Sedangkan mahasiswa Rwanda kerapkali menggunakan bahasa Inggris selama pembelajaran dan tidak mau mengungkapkan maksud melalui bahasa Indonesia karena memiliki ketakutan jika terjadi salah dalam pengucapan.

Berbagai bentuk strategi komunikasi verbal maupun nonverbal yang digunakan oleh mahasiswa Turkmenistan dan Rwanda serta faktor-faktor yang melatarbelakangi penggunaannya menjadi perhatian utama dalam penelitian ini. Selain itu, perbedaan strategi komunikasi diantara keduanya dan berbagai hambatan yang ditemukan dalam penggunaan strategi komunikasi juga dibahas dalam penelitian ini. Mempelajari bahasa umumnya melalui lima tahap yakni trial and error, mengingat-ingat, menirukan, mengasosiasikan, dan menganalogi [8]. Keseluruhan tahap tersebut akan selalu berkaitan dengan penggunaan strategi komunikasi pemelajar BIPA untuk mengurangi kesenjangan saat terjadi interaksi pembelajaran di dalam kelas.

\section{METODE PENELITIAN}

Penelitian ini merupakan penelitian deskriptif kualitatif dengan strategi studi kasus, yaitu suatu bentuk penelitian yang bertujuan untuk mendeskripsikan atau menggambarkan fenomenafenomena yang ada, baik fenomena alamiah ataupun direkayasa manusia [9]. Sumber data 
dalam penelitian ini adalah mahasiswa BIPA asal Turkmenistan dan Rwanda. Adapun data penelitian berupa perilaku verbal dan nonverbal yang dikemas dalam strategi komunikasi saat pembelajaran berlangsung. Dalam penelitian ini teknik observasi dan wawancara digunakan sebagai metode pengumpulan data sedangkan teknik uji validitas penelitian ini menggunakan triangulasi metode. Artinya, keseluruhan data yang diperoleh melalui observasi, wawancara, dan analisis dokumen dibandingkan. Teknik analisis data penelitian berupa analisis model interaktif yang dikembangkan oleh Miles dan Huberman. Analisis data dilakukan melalui (1) reduksi data yaitu proses penyederhanaan data yang dilakukan melalui seleksi data, (2) paparan data yaitu upaya menampilkan data secara jelas dan mudah dipahami dalam bentuk paparan naratif, (3) analisis data yaitu mengkaji data berdasarkan teori, dan (4) penyimpulan yaitu langkah yang dilakukan berdasarkan pola data yang muncul secara sistematis, hingga data mencapai titik jenuh. Pengambilan kesimpulan dilakukan ketika tidak ditemukan lagi pola data yang baru [10].

\section{HASIL DAN PEMBAHASAN}

Terdapat dua belas strategi komunikasi yang ditemukan oleh peneliti pada peristiwa komunikasi yang dilakukan oleh mahasiswa asal Turkmenistan dan Rwanda saat pembelajaran di dalam kelas. Strategi komunikasi yang ditemukan adalah strategi komunikasi dalam bentuk verbal (lisan dan tulis) dan nonverbal. Keduabelas penemuan tersebut adalah sebagai berikut. Pertama adalah pelesapan. Pelesapan merupakan penghilangan kata depan, imbuhan, dan subjek baik secara lisan maupun tulis karena penutur kurang menguasai bahasa kedua yang sedang dipelajari. Peneliti menemukan bahwa pelesapan yang paling dominan dilakukan mahasiswa Turkmenistan dan Rwanda adalah pelesapan imbuhan. Misalnya, mahasiswa Turkmenistan berkata "Pulpen saya bawa Jo". Maksud ungkapan tersebut adalah "Pulpen saya dibawa Jo". Pelesapan dilakukan karena mahasiswa Turkmenistan baru menguasai beberapa kata dasar dalam bahasa Indonesia. Contoh bentuk pelesapan yang lain adalah pelesapan dalam tuturan mahasiswa Rwanda ketika ia berkata "Saya membuat Eric sarapan tadi pagi". Maksud tuturan tersebut adalah "Saya membuatkan Eric sarapan tadi pagi". Mahasiswa Turkmenistan adalah mahasiswa program darmasiswa tingkat dasar yang masih belajar berbagai kata dalam bahasa Indonesia. Mengingat ia tidak bisa berbahasa Inggris, maka di tahap awal pembelajaran pengajar lebih menekankan pada pendekatan behaviorisme. Hal ini dilakukan melalui proses stimulus-respons [11]. Sedangkan mahasiswa asal Rwanda adalah mahasiswa BIPA level 2 yang memiliki penguasaan kosa kata lebih banyak daripada mahasiswa asal Turkmenistan. Akan tetapi meskipun demikian, mahasiswa Rwanda juga masih kerap melakukan pelesapan karena ia masih berada di tahap mengingat-ingat. Hal ini sesuai dengan pendapat [8] yang menjelaskan bahwa dalam mempelajari bahasa, pemelajar akan melalui lima tahap yakni trial and error, mengingat-ingat, menirukan, mengasosiasikan, dan menganalogi.

Kedua adalah pengulangan tuturan. Hal ini kerap dilakukan oleh pemelajar ketika menghadapi sebuah pertanyaan. Misalnya, ketika pengajar berkata "Mahri sudah sarapan?" kepada mahasiswa Turkmenistan, maka sebelum menjawab pertanyaan tersebut, mahasiswa Turkmenistan berkata "Sudah sarapan?" sebagai wujud pengulangan tuturan. Peristiwa pengulangan tuturan terjadi karena pemelajar tidak memahami maksud dari pertanyaan mitratutur. Sedangkan pengulangan tuturan yang dilakukan oleh mahasiswa Rwanda terlihat ketika pengajar berkata "Pukul berapa Anda belajar?". Pertanyaan tersebut menimbulkan kesalahan makna yang diterima oleh mahasiswa Rwanda karena ia hanya mengerti jika makna 'pukul' adalah 'mengetuk dengan sesuatu yang keras' sehingga sebelum menjawab pertanyaan ia melakukan pengulangan tuturan berupa "Pukul berapa Anda belajar?". Pengulangan tuturan 
merupakan bentuk strategi komunikasi yang wajar dilakukan oleh pemelajar asing untuk memperoleh kejelasan terhdap topik komunikasi yang belum mereka pahami [1]. Ketiga adalah peminjaman istilah asing berupa bahasa Inggris dan bahasa ibu. Misalnya, ketika mahasiswa Turkmenistan ingin berkata "Saya ingin makan" tetapi ia berkata "Saya ingin ecmb" karena ia lupa kata 'makan' dalam bahasa Indonesia sehingga ia menggunakan bahasa Rusia yang merupakan bahasa ibunya. Sedangkan mahasiswa Rwanda lebih sering menggunakan istilah asing seperti "Yesterday saya beli buku bersama Husein" atau "Harga buku saya fifty thousand". Kebanyakan pemelajar bahasa memiliki masalah dengan mengomunikasikan konsep-konsep baru. Misalnya dalam konsep angka, mungkin saja mereka sudah memahami angka satu hingga sepuluh dalam bahasa Indonesia. Namun jika angka puluhan, ratusan, ribuan atau lebih mereka cenderung bingung mengembangkan konsep angka sehingga memilih untuk melakukan campur kode [12].

Keempat adalah penggunaan koreksi diri. Misalnya, mahasiswa Turkmenistan berkata “Belajar, setiap malam saya belajar”. Pada kalimat tersebut kata 'belajar' diulang dua kali sebagai wujud koreksi diri bagi mahasiswa Turkmenistan untuk meyakinkan diri bahwa kata yang ia pilih adalah benar. Sedangkan contoh koreksi diri yang dilakukan oleh mahasiswa Rwanda adalah "Kemarin keluarga saya datang saya Solo, kemarin keluarga saya datang ke Solo". Pada kalimat tersebut, terlihat bahwa mahasiswa Rwanda secara cepat melakukan koreksi diri untuk membetulkan kalimatnya sebelum pengajar mengoreksinya. Kesalahan, baik secara verbal maupun tulis dipengaruhi oleh beberapa faktor yang menyebabkan pengajar diharapkan bisa memahami kondisi setiap pemelajarnya untuk mengatasi setiap permasalahan berupa kesalahan berbahasa yang timbul selama pembelajaran [13]. Membiarkan mahasiswa melakukan koreksi diri adalah salah satu langkah pengajar untuk memahami kondisi pemelajarnya agar mereka terbiasa menyadari kesalahannya dalam berbahasa.

Kelima adalah penggunaan kata serupa yang berdekatan maknanya. Seringkali pemelajar asing hanya menguasai satu bentuk kata dalam konteks tertentu tanpa mengetahui penerapan yang lebih sesuai. Misalnya, mahasiswa Turkmenistan berkata "Saya bukan suka susu". Ia hanya memahami bahwa kata 'bukan' digunakan untuk segala sesuatu yang bermakna penolakan. Padahal, maksud yang ingin ia utarakan adalah "Saya tidak suka susu". Hal ini sejalan dengan yang dilakukan oleh mahasiswa Rwanda ketika ia berkata "Saya mencukur jenggot" padahal yang ia maksud adalah mencukur kumis. Mahasiswa Rwanda beranggapan bahwa semua rambut di bawah hidung adalah jenggot sehingga ia menggunakannya sebagai wujud strategi komunikasi verbal. Keenam adalah nada gantung. Strategi komunikasi berupa nada gantung digunakan pemelajar saat menginginkan bantuan secara tidak langsung kepada mitratutur. Misalnya ketika pengajar membawa media flash card, mahasiswa Turkmenistan berkata "Bisa pegang?". Maksud dari tuturan tersebut adalah "Bolehkah saya memegang ini (flasch card)?". Contoh lainnya adalah ketika pengajar membawa makanan khas Solo berupa ampyang, mahasiswa Rwanda bertanya "Bagaimana rasa?". Maksud dari tuturan tersebut adalah ia ingin menanyakan bagaimanakah rasa dari ampyang. Koreksi diri, penggunaan kata serupa, dan nada gantung adalah wujud kompetensi yang dimiliki oleh pemelajar BIPA untuk mengimbangi peristiwa tuturan dengan penutur asli. Kompetensi yang dimaksud dalam konteks belajar bahasa adalah perilaku yang mencakup penggunaan tata bahasa, melakukan fungsi linguistik, penggunaan wujud leksikal yang berbeda, dan sejumlah perilaku lain yang terlibat dalam menggunakan bahasa [8].

Ketujuh adalah metonimia. Pemelajar sering menggunakan nama produk barang di Indonesia untuk mempermudah mereka dalam menyampaikan maksud ketika berkomunikasi. Misalnya, mahasiswa Turkmenistan berkata "Setiap pagi saya minum aqua". Arti dari tuturan tersebut adalah mahasiswa Turkmenistan ingin berkata bahwa ia setiap pagi minum air putih 
tetapi untuk menyatakan maksud 'air putih', ia menggunakan metonimia yakni 'aqua'. Contoh lain penggunaan metonimia adalah ketika mahasiswa Rwanda berkata "Saya ke sini naik Avanza'. Hal ini terjadi karena proses pembelajaran bahasa melibatkan penguasaan tugas yang tak terhitung jumlahnya sehingga menyebabkan pemelajar menggunakan kaitan kata yang lebih mudah untuk mewakili maksud, salah satunya dengan menyebut merk barang tertentu [14]. Kedelapan adalah topikalisasi, yakni strategi komunikasi yang dapat dilakukan secara lisan maupun tulis untuk memilih suatu topik yang lebih fokus guna mempermudah pemilihan kosa kata. Misalnya, mahasiswa Turkmenistan berkata "Kita bicara keluarga saja”, artinya ia ingin mengajak teman-temannya membahas tentang keluarga dan hal ini akan berkaitan dengan kosa kata yang akan digunakan seperti ibu, ayah, adik, kakak, paman, dan bibi. Topikalisasi juga dilakukan oleh mahasiswa Rwanda ketika ia berkata "Ayo, cerita gambar ini". Tuturan tersebut terjadi ketika mahasiswa Rwanda dipinjami media gambar oleh pengajarnya untuk membedakan nama-nama aktivitas dalam bahasa Indonesia. Kesembila adalah balikan. Strategi komunikasi berupa balikan digunakan oleh pemelajar saat menanyakan sesuatu untuk memperoleh tanggapan yang lebih cepat dari pengajar. Dalam bahasa Inggris hal ini dikenal dengan istilah question tag. Misalnya adalah "Ibu sudah mencuci, sudah?" dan "Anak ibu sekolah, ya?".Kebanyakan pemelajar bahasa asing memiliki masalah dengan mengomunikasikan konsep-konsep baru. Artinya, ketika pemelajar belum menguasai konsep baru dari bahasa kedua maka ia akan memiliki kecenderungan untuk menggunakan konsep bahasa yang ia kuasai, misalnya question tag dalam bahasa Inggris [12].

Kesepuluh adalah pemakaian reduksi untuk menghindari topik. Misalnya ketika mahasiswa Turkmenistan menghadapi pertanyaan "Kenapa kamu tidak sarapan?", ia justru menunjuk gambar dan bertanya kepada pengajar "Ini gambar apa?". Hal tersebut terjadi karena ia tidak bisa menjelaskan alasannya tidak sarapan dan mengalihkan pembicaraan dengan menanyakan hal lain kepada pengajarnya. Kesebelas adalah gerak tubuh. Gerak tubuh merupakan salah satu wujud peragaan yang dilakukan dalam strategi komunikasi nonverbal. Misalnya, mahasiswa Turkmenistan menggelengkan kepalanya saat ia ditanyai ketika kuliah di Turkmenistan jurusan apa yang ia ambil. Tetapi karena ia tidak memahami maksud pertanyaan tersebut, ia hanya menggelengkan kepala dan tersenyum. Selanjutnya adalah mahasiswa Rwanda mengepalkan tangan ketika ingin berkata bahwa sifat besi adalah keras. Keduabelas adalah realia, yakni benda-benda sekitar yang digunakan pemelajar untuk menjelaskan sesuatu. Misalnya, mahasiswa Turkmenistan memegang pulpen untuk bertanya "Apakah ini pensil?". Begitu pula dengan mahasiswa Rwanda yang memegang meja sambil bertanya "Ini kursi?". Strategi komunikasi nonverbal sangat bermanfaat untuk menggantikan kata bahasa target yang hilang sehingga strategi komunikasi nonverbal sangatlah penting untuk dilakukan [15].

Strategi komunikasi nonverbal lebih banyak digunakan oleh mahasiswa Turkmenistan karena ia tidak menguasai bahasa Inggris dan bahasa Indonesia. Tujuan dari pembelajaran bahasa asing adalah untuk membuat pemelajar memiliki kemampuan menggunakan bahasa secara fleksibel [16]. Hanya saja, pemelajar sering mengalami kendala untuk melakukan strategi komunikasi itu sendiri sehingga maksud yang ingin disampaikan masih mengalami hambatan. Kurangnya percaya diri, rasa takut, dan malu adalah beberapa faktor internal yang menyebabkan pemelajar hanya diam dan tidak menggunakan strategi komunikasi apapun untuk membantu mereka dalam menghadapi kesenjangan dalam berkomunikasi. Kelas yang heterogen menyebabkan pengajar tidak bisa secara maksimal memberikan teknik pengajaran untuk memeratakan tercapainya tujuan pembelajaran dan hal ini justru semakin membuat pemelajar kebingungan dalam menentukan strategi komunikasi untuk mengimbangi peristiwa tuturan yang berlangsung [17]. 
Situasi dan interaksi selama pembelajaran merupakan hal penting bagi pemelajar guna mendapatkan bahasa dan budaya baru [18]. Pilihan strategi komunikasi menunjukkan variasi signifikan karena hanya ada hubungan kecil antara kemampuan bahasa dan persepsi bahasa [19]. Artinya, keseluruhan strategi komunikasi yang digunakan oleh mahasiswa Turkmenistan dan Rwanda merupakan pilihan pemelajar itu sendiri dan mereka beranggapan bahwa strategi komunikasi tersebut dapat dipahami oleh mitratutur sehingga komunikasi dapat berlangsung dengan baik. Secara dominan, strategi komunikasi yang paling sering muncul dari kedua mahasiswa tersebut adalah alih bahasa dan campur bahasa yang terkemas dalam wujud strategi berupa peminjaman istilah asing [20].

\section{SIMPULAN}

Ada dua belas bentuk strategi komunikasi yang digunakan oleh mahasiswa asal Turkmenistan dan Rwanda dalam kegiatan pembelajaran BIPA. Kedua belas bentuk strategi komunikasi tersebut meliputi pelesapan, pengulangan tuturan, peminjaman istilah asing, koreksi diri, sinonim, nada gantung, metonimia, topikalisasi, balikan, penghindaran topik, gerak tubuh, dan realia. Kedua pemelajar tersebut memiliki perbedaan strategi komunikasi karena perbedaan level pembelajaran, budaya, bahasa ibu, dan jenis huruf. Faktor pendukung terjadinya strategi komunikasi adalah keinginan pemelajar untuk mampu mengimbangi peristiwa komunikasi yang berlangsung meskipun belum menguasai bahasa Indonesia sepenuhnya. Sedangkan faktor penghambat terjadinya strategi komunikasi adalah adanya rasa takut, kurang percaya diri, dan malu sehingga penggunaan strategi komunikasi yang digunakan pemelajar tidak mengurangi kesenjangan dalam berkomunikasi. Selain itu, pengajar kurang memperhatikan aspek heterogenitas di dalam kelas sehingga teknik pengajarannya terkadang tidak bisa memeratakan capaian tujuan pembelajaran.

\section{REFERENCES}

[1] D. Supriyanto, "Strategi Komunikasi Pemelajar BIPA Level A1: Studi Kasus Pusat Kebudayaan Indonesia di Cairo," Ling. Hum., vol. 15, no. April, 2018.

[2] E. Tarone, "Communication Strategies, Foreigner Talk, and Repair in Interlanguage," Lang. Learn., 1980.

[3] R. Ellis, Understanding Second Language Acquisition. 1986.

[4] R. K. Ningrum, H. J. Waluyo, and R. Winarni, "BIPA (Bahasa Indonesia Penutur Asing) sebagai upaya internasionalisasi universitas di Indonesia," 1st Educ. Lang. Int. Conf. Proc., pp. 726-732, 2017.

[5] Y. Purwiyanti, S. Suwandi, and N. Andayani, "Strategi Komunikasi Pemelajar Bahasa Indonesia bagi Penutur Asing Asal Filipina," Ranah J. Kaji. Bhs., 2017.

[6] Y. G. Sedelkina and O. V. Smirnova, "Teaching foreign languages for spesific purposes to students of high schools of fine arts," J. Sci. Educ., 2017.

[7] H. Nugroho, "Pemertahanan Bahasa Sebagai Strategi Komunikasi Pada Kegiatan Tutorial ( Pembelajar BIPA Kelas Pemula ),” vol. 1, no. 1, pp. 23-31, 2016.

[8] E. Subali, "Konsep Bilingualisme dan Pembelajaran Bahasa Indonesia Bagi Penutur Asing," J. Sos. Hum., 2015.

[9] H. Chaiklin, "Case Study Research: Design and Methods," J. Nerv. Ment. Dis., 1991.

[10] M. B. Miles and M. A. Huberman, Analisis Data Kualitatif: Buku Sumber Tentang Metode-Metode Baru. 2012.

[11] S. F. McLaughlin, "Verbal behavior by B.F. Skinner: Contributions to analyzing early language learning.," J. Speech Lang. Pathol. - Appl. Behav. Anal., 2010. 
[12] A. Maleki, "Techniques to Teach Communication Strategies," J. Lang. Teach. Res., 2010.

[13] N. Anjarsari, S. Suwandi, and S. Mulyono, “'Analisis Kesalahan Pemakaian Bahasa Indonesia dalam Karangan Mahasiswa Penutur Bahasa Asing di Universitas Sebelas Maret,"' J. Penelit. Bahasa,Sastra Indones. Dan Pengajarannya, 12302-6405, 2007.

[14] H. Alrefaie and A. Ramsay, "Supporting Language Learners with the Meanings of Closed Class Items," Int. J. Artif. Intell. Appl., 2015.

[15] V. R. Doqaruni and H. Najjari, "Communication Strategies Revisited : Looking beyond Interactional and Psycholinguistic Perspectives," J. Appl. Linguist., 2013.

[16] Y. Yu, "Problems in and Solutions to Oral English Teaching in Rural Middle SchoolA Case Study in ZhaoCheng Middle School," J. Lang. Teach. Res., 2019.

[17] E. A. Indrariani, "Pola Penggunaan Bahasa dalam Interaksi Pembelajaran Bahasa Indonesia Untuk Mahasiswa Asing (BIPA)," J. Bhs. Ling. Sci., 2016.

[18] S. Papaefthymiou-Lytra, "Interactive language teaching. Wilga Rivers (Ed.). New York: Cambridge University Press, 1987. Pp. xvi + 228.," Appl. Psycholinguist., 1988.

[19] T. Zhao and C. Intaraprasert, "Use of communication strategies by tourism-oriented EFL learners in relation to gender and perceived language ability," English Lang. Teach., 2013.

[20] K. Saddhono, "Integrating culture in Indonesian language learning for foreign speakers at Indonesian universities," J. Lang. Lit., vol. 6, no. 2, 2015. 